\title{
The Anatomy of the Supraclavicular Nerve During Surgical Approach to the Clavicular Shaft
}

\author{
Tyler Nathe MD, Susan Tseng MD, Brad Yoo MD
}

Received: 17 January 2010/Accepted: 21 September 2010/Published online: 9 October 2010

(C) The Author(s) 2010. This article is published with open access at Springerlink.com

\begin{abstract}
Background Surgery for clavicular shaft fractures is becoming more common but incisional and chest wall numbness reportedly occurs in $10 \%$ to $29 \%$ of patients. This may be the result of iatrogenic injury to the supraclavicular nerve branches.

Questions/purposes We determined if there was a predictable branching pattern of the supraclavicular nerve at the anterior clavicular border and determined the distances to these nerves from clavicular landmarks.

Methods We performed an anatomic dissection along the anterior border of the long axis of the clavicle in 37 cadavers. The branches of the supraclavicular nerve were identified at the anterosuperior clavicular border and the distances from these nerves to palpable bony landmarks were measured.

Results Ninety-seven percent of specimens had a medial and a lateral branch of the supraclavicular nerve. Nearly half $(49 \%)$ possessed an additional intermediate branch. No branch was found within $2.7 \mathrm{~cm}$ of the sternoclavicular joint or within $1.9 \mathrm{~cm}$ of the acromioclavicular joint. Between these two positions, there was wide variability in nerve branch location.
\end{abstract}

One or more of the authors (TN, BY) have received funding from a grant from AO North America.

Each author certifies that his or her institution approved the human protocol for this investigation, that all investigations were conducted in conformity with ethical principles of research, and that informed consent for participation in the study was obtained.

T. Nathe $(\bowtie)$, S. Tseng, B. Yoo

Department of Orthopaedic Surgery,

University of California at Davis, 4860 Y Street,

Suite 3800, Sacramento, CA 95817, USA

e-mail: tyler.nathe@ucdmc.ucdavis.edu
Conclusions There were two or three branches of the supraclavicular nerve crossing the clavicle $97 \%$ of the time and a wide variability of the location of these branches outside the safe zones.

Clinical Relevance There are safe zones within $2.7 \mathrm{~cm}$ of the sternoclavicular joint and $1.9 \mathrm{~cm}$ of the acromioclavicular joint. Between these safe zones, the location of the nerve branches is variable and the surgeon must use meticulous dissection if he or she wishes to prevent transection.

\section{Introduction}

Historically, clavicular shaft fractures are treated without surgery with nonunion rates reported as low as $0.1 \%[14$, 19]. However, some surgeons suggest young adults with displaced clavicular shaft fractures or displaced distal clavicular fractures may have better function from restoration of natural anatomy $[2,13,15]$. The indications for open surgery are more clear when there is a painful nonunion or malunion $[1,3,4,6,12,16,23]$. Whether performed acutely or on a delayed basis, the surgical approach along the long axis of the clavicle carries a risk of proximal chest wall or peri-incisional numbness that could be from supraclavicular nerve injury. The rate of incisional and proximal chest wall numbness ranges from $10 \%$ to $29 \%$ after operative fixation of the clavicle [2, 20, 21].

The supraclavicular nerve is a superficial sensory nerve originating from the $\mathrm{C} 3$ and $\mathrm{C} 4$ nerve roots of the superficial cervical plexus. This nerve arborizes proximal to the clavicle and provides sensation over the clavicle, anteromedial shoulder, and proximal chest $[5,8]$. The branching pattern and distances to the nerves from anatomic landmarks at the level of the clavicle are unknown. If the 
precise location of the traversing nerve branches were known, preservation of these structures could possibly prevent postoperative morbidity.

We asked whether the terminal branches of the supraclavicular nerve would course over the clavicle in a predictable pattern and quantified distances of each supraclavicular nerve branch with respect to clinically appreciable clavicular landmarks.

\section{Materials and Methods}

We obtained 37 shoulders from adult fresh or embalmed cadavers without a history of surgical or mechanical trauma to the thorax or shoulder girdle. All specimens were free of gross deformity and surgical incisions. Once all measurements had been made, the specimens were confirmed to be skeletally mature by verification of a closed clavicular physis. All dissections were performed under the supervision of the senior author (BY). An 18-gauge needle was localized at the anterior border of the sternoclavicular (SC) and acromioclavicular (AC) joints. The clavicle length was defined as the distance between these two points. We obtained all measurements three separate times using digital calipers with a tolerance to one-hundredth of a millimeter and then averaged these three values to one-hundredth of a millimeter for the final value. We noticed no anatomic differences between the embalmed and fresh specimens.

Anatomic dissection at the clavicle was made using a transverse incision through skin at the anterosuperior clavicular border. This incision was the full length of the clavicle in line with the surgical approach as described by Kabak et al. [11]. Then meticulous soft tissue dissection identified the terminal branches of the supraclavicular nerve where they traversed the anterosuperior border of the clavicle (Fig. 1). The distances from the SC and AC joints to each crossing nerve were measured similarly to onehundredth of a millimeter three separate times under direct supervision of the senior author (BY). The average of the three measurements was calculated to one-hundredth of a

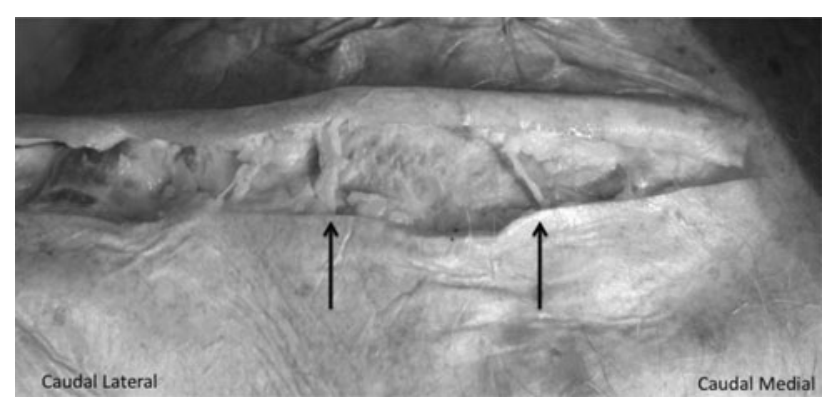

Fig. 1 A photograph of a specimen from Group 1 shows the medial and lateral supraclavicular nerve branches. millimeter and was used as the final value for our calculations. After measurements, the presumed nerve was divided and confirmed by the presence of nerve fascicles.

We analyzed the data by dividing the branching pattern into two groups and one anomalous specimen with only one crossing nerve branch. Group 1 consisted of two nerve branches that were found medially and laterally (Fig. 1). Group 2 consisted of three nerve branches, the same medial and lateral branches as seen in Group 1 with an additional intermediate branch found between the medial and lateral branches.

The average distances from the SC and AC joints to the nerve branches were calculated with two standard deviations (SDs) to determine the $95 \%$ confidence interval (CI) of locating the particular branch within a given distance from two bony landmarks. This was calculated with the actual gross distance measured and as a percentage of each clavicle's length rounded to one-hundredth of a percent. We used Microsoft Excel (Microsoft Inc, Redmond, WA, USA) to calculate these values.

\section{Results}

The supraclavicular nerve branched over the clavicle in a predictable pattern. Ninety-seven percent of specimens (36 of 37) had medial and lateral branches. An additional $49 \%$ of specimens (18 of 37) had an intermediate branch. One specimen had only a medial branch (2.7\% of specimens). Group 1 had medial and lateral nerve branches (49\% of specimens). Group 2 had medial, intermediate, and lateral nerve branches (49\% of specimens). We did not observe any other variants such as intraosseous nerves.

Although there was a predictable pattern of two or three nerves crossing the clavicle in $97 \%$ of specimens, we observed considerable variability in the distance to these nerves from clinically appreciable landmarks. There was a safe zone where no medial nerve was found within $2.7 \mathrm{~cm}$ of the sternoclavicular joint and no lateral nerve was found within $1.9 \mathrm{~cm}$ of the acromioclavicular joint. In Group 1 (two nerves), the distance from the sternoclavicular joint to the medial branch within 2 SDs was $33.0 \mathrm{~mm}$ to $63.4 \mathrm{~mm}$ and $63.5 \mathrm{~mm}$ to $121.9 \mathrm{~mm}$ to the lateral branch (Table 1). There was a 95\% probability of finding the branches within these distances and only a $0.1-\mathrm{mm}$ interval between these zones. As a percentage relative to each clavicle length, the distance from the SC joint to the medial branch within 2 SDs was $21.7 \%$ to $43.1 \%$ the length of the clavicle. The SC joint to the lateral branch was $44.7 \%$ to $79.5 \%$ the length of the clavicle (Table 2). For Group 2 (three nerves), the distance to the medial branch from the SC joint within 2 SDs was $20.3 \mathrm{~mm}$ to $60.3 \mathrm{~mm}$ for the medial nerve, $33.1 \mathrm{~mm}$ to $104.3 \mathrm{~mm}$ for the intermediate nerve, and 
Table 1. Nerve branch distance to SC or AC joint for Group 1

\begin{tabular}{lllll}
\hline Clavicle length & SC to medial branch & SC to lateral branch & AC to medial branch & AC to lateral branch \\
\hline $149.2 \mathrm{~mm}^{*}$ & $48.2 \mathrm{~mm}^{*}$ & $92.7 \mathrm{~mm}^{*}$ & $97.4 \mathrm{~mm}^{*}$ & $59.7 \mathrm{~mm}^{*}$ \\
$\pm 20.6 \mathrm{~mm}^{\dagger}$ & $\pm 15.2 \mathrm{~mm}^{\dagger}$ & $\pm 29.2 \mathrm{~mm}^{\dagger}$ & $\pm 35.6 \mathrm{~mm}^{\dagger}$ & $\pm 43.4 \mathrm{~mm}^{\dagger}$ \\
\hline
\end{tabular}

$*=$ average ${ }^{\dagger}=$ two SDs; $\mathrm{SC}=$ sternoclavicular; $\mathrm{AC}=$ acromioclavicular.

Table 2. Nerve branch distance as a percentage of total clavicle length for Group 1

\begin{tabular}{llll}
\hline $\begin{array}{l}\text { SC to medial } \\
\text { branch }\end{array}$ & $\begin{array}{l}\text { SC to lateral } \\
\text { branch }\end{array}$ & $\begin{array}{l}\text { AC to medial } \\
\text { branch }\end{array}$ & $\begin{array}{l}\text { AC to lateral } \\
\text { branch }\end{array}$ \\
\hline $32.4 \%^{*}$ & $62.1 \% *$ & $65.0 \%^{*}$ & $40.1 \% *$ \\
$\pm 10.7 \%^{\dagger}$ & $\pm 17.4 \%^{\dagger}$ & $\pm 18.2 \%^{\dagger}$ & $\pm 30.1 \%^{\dagger}$ \\
\hline
\end{tabular}

$*=$ average $^{\dagger}=$ two $\mathrm{SDs} ; \mathrm{SC}=$ sternoclavicular; $\mathrm{AC}=$ acromioclavicular.

$62.6 \mathrm{~mm}$ to $142.0 \mathrm{~mm}$ for the lateral nerve (Table 3). There was $95 \%$ probability of finding the branches within these distances and an overlap of the zones where the branches cross the clavicle. As a percentage relative to each clavicle length, the distance from the SC joint to the medial branch within 2 SDs was between $16.1 \%$ and $37.7 \%$ the length of the clavicle. The distance from the SC joint to the intermediate branch was between $26.9 \%$ and $64.3 \%$ the length of the clavicle. The distance to the lateral branch was between $47.5 \%$ and $89.3 \%$ the length of the clavicle (Table 4). A graphic representation of the $95 \%$ confidence interval of each nerve for Groups 1 and 2 shows the distribution of the nerve branches (Fig. 2).

\section{Discussion}

Although clavicle fractures have been treated without surgery with union rates as low as $0.1 \%$ [14], evidence suggests a subset of patients may benefit functionally from restoration of the natural anatomy $[2,13,15]$. The rate of incisional and proximal chest wall numbness has been reported from $10 \%$ to $29 \%$ after operative treatment of clavicle fractures $[2,20,21]$. The supraclavicular nerve is a superficial sensory nerve that crosses the clavicle and provides sensation over the clavicle, anteromedial shoulder, and proximal chest $[5,8]$. In theory, injury to these nerve branches could be reduced by knowledge of their precise location. We asked whether the terminal branches of the supraclavicular nerve would course over the clavicle in a predictable pattern and quantified distances of each supraclavicular nerve branch with respect to clinically appreciable clavicular landmarks.

Limitations to the study should be addressed. First, although the dissection was as careful as possible, the native location of the supraclavicular nerve may have been altered during the dissection process. The slight difference in distance to the nerve branches, however, is unlikely to change the overall conclusions of this study. Second, it is possible, although unlikely, that some nerve branches were inadvertently transected and overlooked during dissection. We made every attempt to record the location of each supraclavicular nerve branch in its anatomic position. Because we found a predictable branching pattern of two or three nerves in $97 \%$ of specimens, this is unlikely to have influenced the results. Third, a large transverse incision that we used was longer than that used for operative stabilization of the clavicle. Therefore, it is unlikely that all

Table 3. Nerve branch distance to SC or AC joint for Group 2

\begin{tabular}{lllllll}
\hline $\begin{array}{l}\text { Clavicle } \\
\text { length }\end{array}$ & $\begin{array}{l}\text { SC to medial } \\
\text { branch }\end{array}$ & $\begin{array}{l}\text { SC to intermediate } \\
\text { branch }\end{array}$ & $\begin{array}{l}\text { SC to lateral } \\
\text { branch }\end{array}$ & $\begin{array}{l}\text { AC to medial } \\
\text { branch }\end{array}$ & $\begin{array}{l}\text { AC to intermediate } \\
\text { branch }\end{array}$ & $\begin{array}{l}\text { AC to lateral } \\
\text { branch }\end{array}$ \\
\hline $149.8 \mathrm{~mm}^{*}$ & $40.3 \mathrm{~mm}^{*}$ & $68.7 \mathrm{~mm}^{*}$ & $102.3 \mathrm{~mm}^{*}$ & $95.8 \mathrm{~mm}^{*}$ & $83.9 \mathrm{~mm}^{*}$ \\
$\pm 29.2 \mathrm{~mm}^{\dagger}$ & $\pm 20.0 \mathrm{~mm}^{\dagger}$ & $\pm 35.6 \mathrm{~mm}^{\dagger}$ & $\pm 39.7 \mathrm{~mm}^{\dagger}$ & $\pm 61.6 \mathrm{~mm}^{\dagger}$ & $\pm 23.9 \mathrm{~mm}^{\dagger}$ & $\begin{array}{l}6.1 \mathrm{~mm}^{*} \\
\pm 67.4 \mathrm{~mm}^{\dagger}\end{array}$
\end{tabular}

$*=$ average $^{\dagger}=$ two SDs; $\mathrm{SC}=$ sternoclavicular; $\mathrm{AC}=$ acromioclavicular.

Table 4. Nerve branch distance as a percentage of total clavicle length for Group 2

\begin{tabular}{lllll}
\hline $\begin{array}{l}\text { SC to medial } \\
\text { branch }\end{array}$ & $\begin{array}{l}\text { SC to intermediate } \\
\text { branch }\end{array}$ & $\begin{array}{l}\text { SC to lateral } \\
\text { branch }\end{array}$ & $\begin{array}{l}\text { AC to medial } \\
\text { branch }\end{array}$ & $\begin{array}{l}\text { AC to intermediate } \\
\text { branch }\end{array}$ \\
\hline $26.9 \%^{*}$ & $45.6 \%^{*}$ & $68.4 \%^{*}$ & $63.8 \%^{*}$ & $\begin{array}{l}\text { AC to lateral } \\
\text { branch }\end{array}$ \\
$\pm 10.8 \%^{\dagger}$ & $\pm 18.7 \%^{\dagger}$ & $\pm 20.9 \%^{\dagger}$ & $\pm 38.6 \%^{\dagger}$ & $\pm 6.6 \%^{*}$ \\
$418.6 \%^{\dagger}$ & $\pm 4.8 \%^{*}$ \\
\hline
\end{tabular}

$*=$ average $^{\dagger}=$ two SDs; $\mathrm{SC}=$ sternoclavicular; $\mathrm{AC}=$ acromioclavicular. 
Fig. 2A-B Graphic representations of the $95 \%$ confidence interval of each nerve for (A) Group 1 and (B) Group 2 show distribution of the nerve branches.

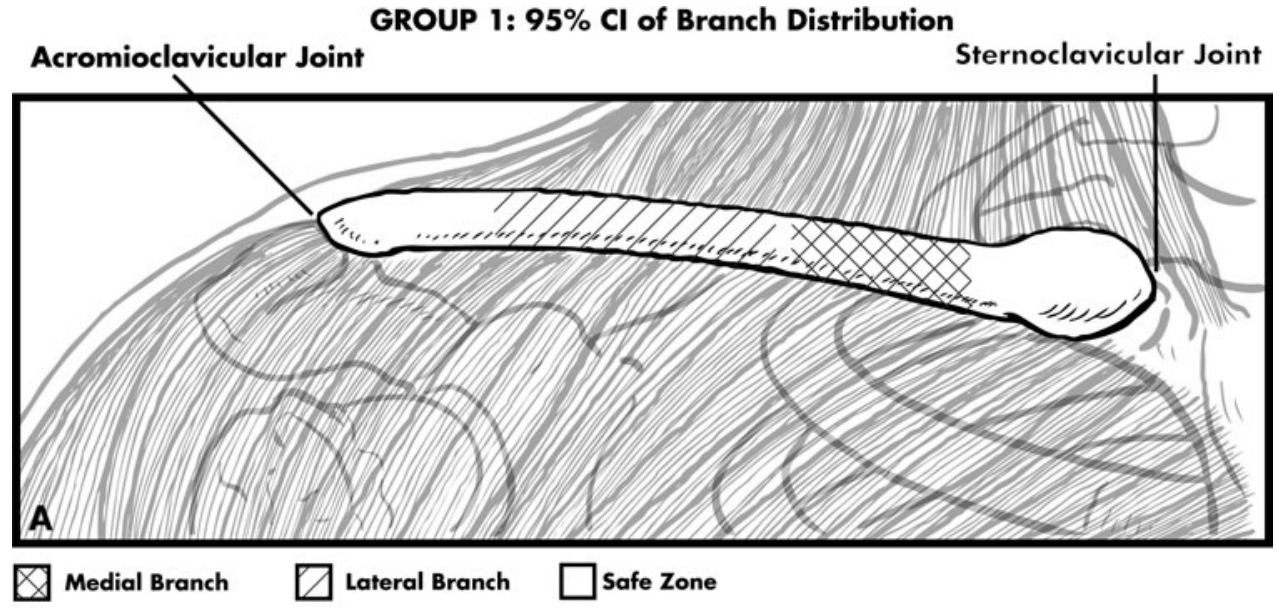

GROUP 1: $95 \% \mathrm{Cl}$ of Branch Distribution

GROUP 2: $95 \% \mathrm{Cl}$ of Branch Distribution

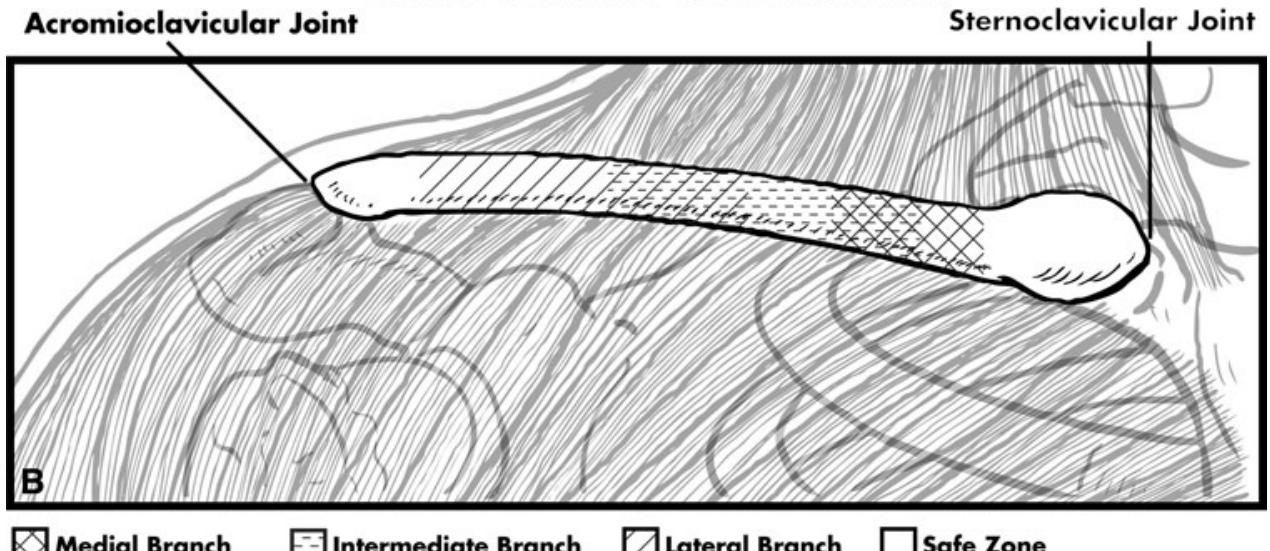

branches will be encountered in a typical surgical case. Fourth, the anatomy could be distorted in the setting of a fracture. This will not change the branching pattern but could change the distances to the nerves. Finally, the clinical impact of injury to a particular nerve branch has not been elucidated. Logic would suggest nerve injury would result in paresthesias in a specific distribution. Yet, injury to one branch may not yield clinical numbness because another branch may provide redundant innervation. This warrants further study.

We found that terminal branches of the supraclavicular nerve cross the clavicle in a predictable pattern. Ninetyseven percent of specimens had medial and lateral branches with $49 \%$ containing an additional intermediate branch. Hovelacque originally described the medial, intermediate, and lateral branches of the superficial cervical plexus [9]. However, he did not describe the different branching patterns in relation to the clavicle.

We defined the distances to each supraclavicular nerve branch with respect to clinically appreciable landmarks. It was our hope to find predictable clinically relevant safe zones between branches of the supraclavicular nerve during a surgical approach to the clavicle. The distances to the branches of the supraclavicular nerve from bony landmarks fall within a wide range over the middle of the clavicle. The medial branch appeared to cross at the clavicle's medial third. The lateral branch showed a trend to cross at the lateral third of the clavicle. When present, the intermediate branch displayed wide variability. In addition to the wide variability in precise location of the branches, there have been multiple anatomic variations described. Gelberman et al. first described supraclavicular nerve entrapment syndrome in a patient in whom the nerve passed through an osseous tunnel in the clavicle [7]. Since then, the osseous tunnel has been confirmed and multiple other anatomic variations have been implicated as a possible cause of this syndrome [10, 17, 18, 22]. There was no zone where one nerve branch was exclusively independent of another adjacent branch. There was never a medial branch within $2.7 \mathrm{~cm}$ of the sternoclavicular joint or a lateral branch within $1.9 \mathrm{~cm}$ of the acromioclavicular joint.

There appears to be a pattern in which the supraclavicular nerve branches cross the clavicle with the majority (97\%) of specimens possessing a medial and a lateral 
branch. The intermediate branch is variable and present $49 \%$ of the time. The precise location of each branch at the clavicle is variable and there is no clinically relevant predictable safe zone between the medial and lateral branches. There are small safe zones medially and laterally with no medial branches found within $2.7 \mathrm{~cm}$ of the sternoclavicular joint and no lateral branches found within $1.9 \mathrm{~cm}$ of the acromioclavicular joint. Between these safe zones the surgeon must use meticulous dissection if he or she wishes to prevent transection.

Open Access This article is distributed under the terms of the Creative Commons Attribution Noncommercial License which permits any noncommercial use, distribution, and reproduction in any medium, provided the original author(s) and source are credited.

\section{References}

1. Boehme D, Curtis RJ Jr, DeHaan JT, Kay SP, Young DC, Rockwood CA Jr. Non-union of fractures of the mid-shaft of the clavicle: treatment with a modified Hagie intramedullary pin and autogenous bone-grafting. J Bone Joint Surg Am. 1991;73: $1219-1226$

2. Canadian Orthopaedic Trauma Society. Nonoperative treatment compared with plate fixation of displaced midshaft clavicular fractures: a multicenter, randomized clinical trial. J Bone Joint Surg Am. 2007;89:1-10.

3. Davids PH, Luitse JS, Strating RP, van der Hart CP. Operative treatment for delayed union and nonunion of midshaft clavicular fractures: $\mathrm{AO}$ reconstruction plate fixation and early mobilization. J Trauma. 1996;40:985-986.

4. Der Tavitian J, Davison JN, Dias JJ. Clavicular fracture non-union surgical outcome and complications. Injury. 2002;33:135-143.

5. Drake RL, Vogl AW, Mitchell AWM. Gray's Anatomy for Students. New York, NY: Churchill Livingstone; 2009.

6. Ebraheim NA, Mekhail AO, Darwich M. Open reduction and internal fixation with bone grafting of clavicular nonunion. J Trauma. 1997;42:701-704.

7. Gelberman RH, Verdeck WN, Brodhead WT. Supraclavicular nerve-entrapment syndrome. J Bone Joint Surg Am. 1975;57:119.

8. Havet E, Duparc F, Tobenas-Dujardin AC, Muller JM, Freger P. Morphometric study of the shoulder and subclavicular innervation by the intermediate and lateral branches of supraclavicular nerves. Surg Radiol Anat. 2007;29:605-610.

9. Hovelacque A. [Anatomy of cranial and spinal nerves and the sympathetic system in human][in French]. Paris, France: Gaston Doin et Cie Ed; 1927.

10. Jelev L, Surchev L. Study of variant anatomical structures (bony canals, fibrous bands, and muscles) in relation to potential supraclavicular nerve entrapment. Clin Anat. 2007;20:278-285.

11. Kabak S, Halici M, Tuncel M, Avsarogullari L, Karaoglu S. Treatment of midclavicular nonunion: comparison of dynamic compression plating and low-contact dynamic compression plating techniques. J Shoulder Elbow Surg. 2004;13:396-403.

12. Manske DJ, Szabo RM. The operative treatment of mid-shaft clavicular non-unions. J Bone Joint Surg Am. 1985;67:1367-1371.

13. McKee MD, Pedersen EM, Jones C, Stephen DJ, Kreder HJ, Schemitsch EH, Wild LM, Potter J. Deficits following nonoperative treatment of displaced midshaft clavicular fractures. $J$ Bone Joint Surg Am. 2006;88:35-40.

14. Neer CS 2nd. Nonunion of the clavicle. JAMA. 1960;172: $1006-1011$

15. Neer CS 2nd. Fracture of the distal clavicle with detachment of the coracoclavicular ligaments in adults. J Trauma. 1963;3: 99-110.

16. O'Connor D, Kutty S, McCabe JP. Long-term functional outcome assessment of plate fixation and autogenous bone grafting for clavicular non-union. Injury. 2004;35:575-579.

17. Omokawa S, Tanaka Y, Miyauchi Y, Komei T, Takakura Y. Traction neuropathy of the supraclavicular nerve attributable to an osseous tunnel of the clavicle. Clin Orthop Relat Res. 2005; 431:238-240.

18. Ottone NE, Medan C. A rare muscle anomaly: the supraclavicularis proprius muscle. Folia Morphol (Warsz). 2009;68:55-57.

19. Rowe CR. An atlas of anatomy and treatment of midclavicular fractures. Clin Orthop Relat Res. 1968;58:29-42.

20. Shen WJ, Liu TJ, Shen YS. Plate fixation of fresh displaced midshaft clavicle fractures. Injury. 1999;30:497-500.

21. Strauss EJ, Egol KA, France MA, Koval KJ, Zuckerman JD. Complications of intramedullary Hagie pin fixation for acute midshaft clavicle fractures. J Shoulder Elbow Surg. 2007;16: 280-284.

22. Tubbs RS, Salter EG, Oakes WJ. Anomaly of the supraclavicular nerve: case report and review of the literature. Clin Anat. 2006; 19:599-601.

23. Wentz S, Eberhardt C, Leonhard T. Reconstruction plate fixation with bone graft for mid-shaft clavicular non-union in semiprofessional athletes. J Orthop Sci. 1999;4:269-272. 